This item was submitted to Loughborough's Research Repository by the author.

Items in Figshare are protected by copyright, with all rights reserved, unless otherwise indicated.

\title{
Thermal interface materials - a review of the state of the art
}

PLEASE CITE THE PUBLISHED VERSION

PUBLISHER

(C) IEEE

VERSION

VoR (Version of Record)

LICENCE

CC BY-NC-ND 4.0

REPOSITORY RECORD

Sarvar, Farhad, David C. Whalley, and Paul P. Conway. 2019. "Thermal Interface Materials - a Review of the State of the Art". figshare. https://hdl.handle.net/2134/4197. 
This item was submitted to Loughborough's Institutional Repository (https://dspace.lboro.ac.uk/) by the author and is made available under the following Creative Commons Licence conditions.

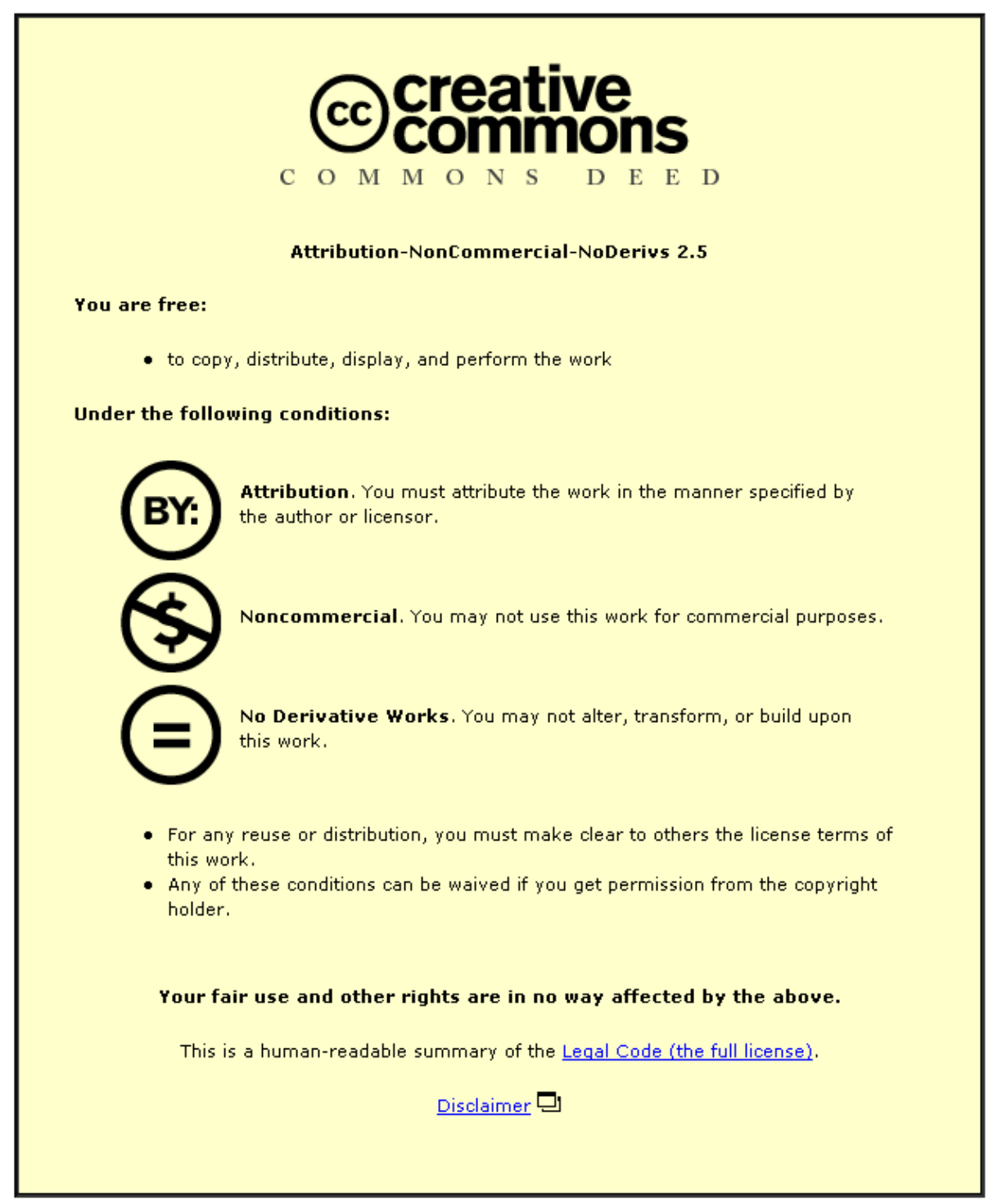

For the full text of this licence, please go to: http://creativecommons.org/licenses/by-nc-nd/2.5/ 


\title{
Thermal Interface Materials - A Review of the State of the Art
}

\author{
Farhad Sarvar, David C. Whalley and Paul P. Conway \\ Wolfson School of Mechanical and Manufacturing Engineering \\ Loughborough University, Loughborough \\ Leics., LE11 3TU, UK \\ Email: F.Sarvar@,lboro.ac.uk, D.C.Whalley@lboro.ac.uk, P.P.Conway@,lboro.ac.uk
}

\begin{abstract}
The past few decades have seen an escalation of power densities in electronic devices, and in particular in microprocessor chips. Together with the continuing trend of reduction in device dimensions this has led to dramatic increase in the thermal issues within electronic circuits. Thermal management is therefore becoming increasingly more critical and fundamental to ensuring that electronic devices operate within their specification. Although a thermal management system may make use of all modes of heat transfer to maintain temperatures within their appropriate limits and to ensure optimum performance and reliability, conductive heat transfer is typically used to spread the heat out from its point of generation and into the extended surface area of a heatsink. To minimise the contact resistance, thermal interface materials (TIMs) are introduced to the joint to fill the air gaps and are an essential part of an assembly when solid surfaces are attached together. This paper will first review the conventional interface materials and then goes on to present a comprehensive review of the emerging state-of-the-art research in the use of carbon nanotube based materials. The paper will also outline the advantages and disadvantages of each TIM category and the factors that need to be considered when selecting an interface material.
\end{abstract}

\section{Introduction}

It is evident that in the past few decades heat generation in both individual power devices and integrated circuits and within complete electronic systems have increased dramatically. For example the maximum thermal power dissipation, measured for the worse-case set of instructions, of a first generation Intel Pentium ${ }^{\circledR}$ II, $233 \mathrm{MHz}$ processor (circa 1997) had a power dissipation of 34.8W [1] compared to the $165 \mathrm{~W}$ [2] dissipated by the latest 64-bit dual-core Intel Xeon ${ }^{\circledR} 7041$ Processor (December 2005) running at a $3.0 \mathrm{GHz}$ clock speed. Thermal management is essential to maintain such electronic devices operating within their specification. A well designed thermal management system will maintain temperatures within the proper limits to ensure optimum performance and reliability.

In general, various interfaces will exist between the high power, heat generating component and the eventual heatsink. Some of these interfaces will consist of permanent bonds, such as solders or adhesives, but often a non-permanent interface will form part of the heat transfer path, e.g. where a component is bolted to a heatsink or between an assembled module and a chassis. When these surfaces are attached together there will almost always be only a small area of actual mechanical contact between the two surfaces at this interface, due to the micro-scale surface roughness and waviness of the surfaces as shown in Figure 1. This will have an impact on the heat conduction across the interface, as there will be gaps filled with low thermal conductivity air. The irregularity of real surfaces is therefore a primary cause of thermal contact resistance. In order to minimise the thermal contact resistance, filler materials are therefore generally required to enhance the contact between the mating surfaces, as shown in Figure 2.

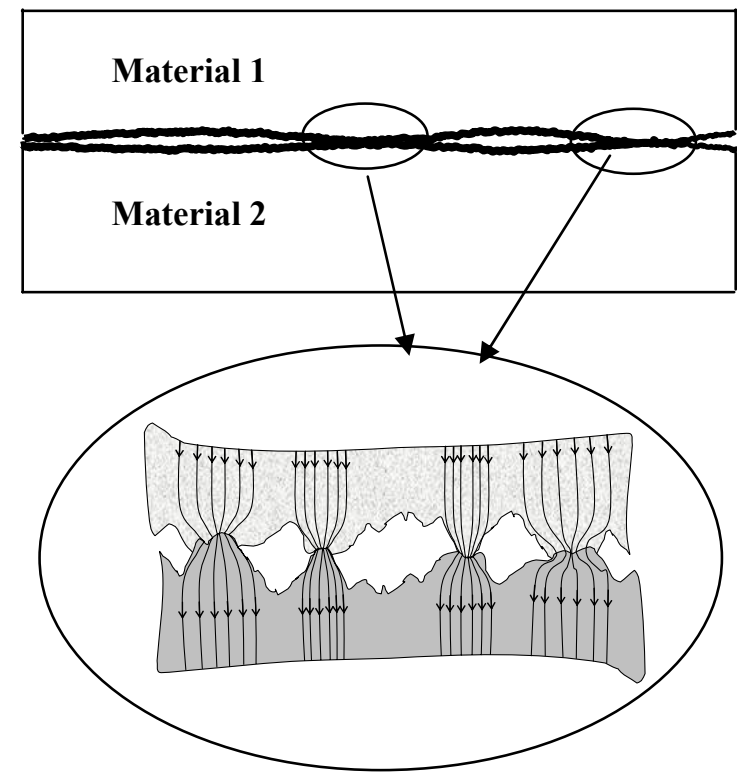

Figure 1 Diagram illustrating the waviness and roughness of two contacting surfaces 


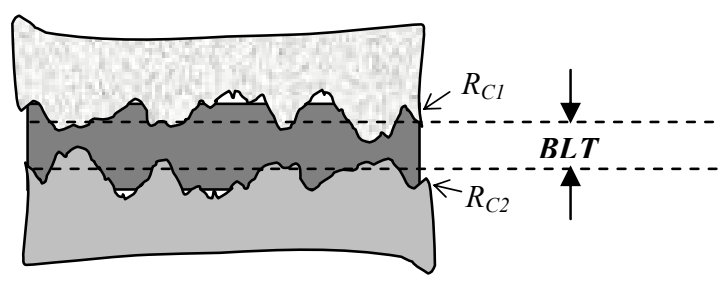

Figure 2 Thermal interface material inserted between the two contacting bodies

The surface flatness, or waviness, is determined by comparing the variance of the height in a specimen to that of a reference standard. For heatsinks, the attachment face should have a flatness less than $4 \mu \mathrm{m}$ per $\mathrm{cm}$ to be considered satisfactory [3]. Surface roughness (finish) is defined as the average deviation from the mean surface height. In general for very low thermal resistance, a surface finish in the range of $1.27-1.5 \mu \mathrm{m}$ is recommended [4]. However, a study by researchers at Thermalloy, using a copper TO-204 (TO-3) package with a typical $0.8 \mu \mathrm{m}$ surface finish, demonstrated that heatsink finishes between $0.4 \mu \mathrm{m}$ and $1.63 \mu \mathrm{m}$ in the presence of a thermal interface material resulted in less than a $2.5 \%$ difference in interface thermal resistance [5].

The effective total thermal resistance at the interface between two materials is a sum of the resistance due to the thermal conductivity of the TIM and contact resistance between the TIM and the two contacting surfaces. This is generally expressed as [6]:

$$
R_{\text {effective }}=\frac{B L T}{k_{\text {TIM }} A}+R_{c_{1}}+R_{c_{2}}
$$

Where $B L T$ and $k_{T I M}$ are the bond line thickness (Figure 2) and thermal conductivity of the interface material respectively and $A$ is the area. $R_{c l}$ and $R_{c 2}$ are contact resistances of the TIM at the boundary with the two surfaces. The contact resistance is influenced by a number of factors including surface roughness, surface flatness, clamping pressure and compressive modulus. To improve the heat dissipation across an interface it is important to minimise the value of $R_{\text {effective. }}$ This can be achieved by reducing the bond line thickness and employing a TIM with the highest possible thermal conductivity. On the other hand reducing surface roughness and applying pressure can reduce contact resistance. A smoother surface reduces the heights and depths of the peaks and valleys that a TIM has to fill and pressure acts to mate the interface material to its surfaces, minimising the amount of air remaining at the interface. Pressure can also reduce thermal resistance of soft materials by reducing the material thickness [7].

Although the use of TIMs helps to improve heat transfer across an interface, it is widely recognised that TIMs increasingly account for most of the system total thermal resistance [8]. Direct solder attach techniques are in this respect very attractive because of their high thermal conductivities (30-86 $\mathrm{W} / \mathrm{mK}$ ), which can reduce thermal resistance. Solders, however, can introduce thermal stress [9] and are difficult to rework and repair, requiring high temperature processing. Even if softer solder materials are used that have low yield stresses, these suffer from poor thermal fatigue resistance and other such unfavourable metallurgical characteristics.

There are currently several types of thermal interface materials available on the market, including:

- Greases

- Phase change materials

- Filled polymer matrices (elastomers) and

- Carbon based materials

Table 1 outlines the important advantages and disadvantages of traditional thermal interface material.

More recently there has been a great deal of research carried out on developing TIMs containing carbon nano-materials such as carbon nanotubes (CNT) for improving thermal contact conductance. This has been generating a lot of interest within the microprocessor manufacturers and reportedly [10] Intel is investigating the feasibility of using carbon nanotube based polymer composites as the thermal interface material between a microprocessor chip and the heat sink. There are also metallic foils, solders and metallic coatings used in certain applications.

\section{Factors to consider when selecting Thermal Interface Materials}

There are a number of factors that must be taken into consideration when selecting a thermal interface material. For any particular application TIM performance, its reliability and installation have to be assessed. Typical characteristics of a TIM that can influence the choice are outlined below:

- Thermal conductivity - A TIM's bulk thermal conductivity determines its ability to transfer heat across the interface and as such has a significant impact on its thermal performance.

- Thermal resistance - as defined by equation 1 and should ideally be as low as possible to 
maintain the device below its operating temperature.

- Electrical conductivity - Some TIMs are electrically conductive but they are generally based on polymers or polymers filled with nonconductive materials where electrical conduction is not an issue.

- Phase change temperature - phase change temperature is the temperature at which the transition from solid to liquid occurs and the interface material fills the gaps, ensuring that all the air is expelled. It is therefore important that melt temperature is below the maximum operating temperature of the device so that it can effectively transfer heat across the interface, but as high as possible to avoid a phase change occurring during shipping. Studies by Bergquist [11] have shown that temperatures as high as $60^{\circ} \mathrm{C}$ can be experienced in transport containers.

Table 1 Advantages and disadvantages of typical thermal interface material

\begin{tabular}{|c|c|c|c|}
\hline \multicolumn{2}{|c|}{ TIM } & Advantages & Disadvantages \\
\hline \multicolumn{2}{|c|}{ 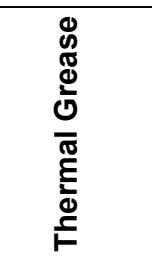 } & $\begin{array}{l}\text { - High thermal conductivity } \\
\text { - Thin joint with minimal attach pressure therefore low } \\
\text { thermal resistance } \\
\text { - No curing required } \\
\text { - Delamination not an issue } \\
\text { - Low cost }\end{array}$ & $\begin{array}{l}\text { - Thermal cycling can result in pump-out and phase separation } \\
\text { - Can be messy and in a manufacturing environment can pollute } \\
\text { assemblies and reflow baths } \\
\text { - Dry-out over time reducing reliability } \\
\text { - Thickness difficult to control } \\
\text { - Excess grease can flow out beyond the edges }\end{array}$ \\
\hline 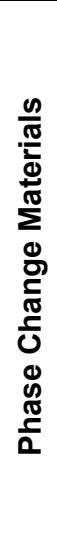 & 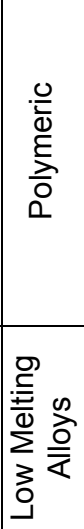 & $\begin{array}{l}\text { - Increased stability and less susceptibility to pump-out } \\
\text { - Easier application and handling compared to greases } \\
\text { - No cure } \\
\text { - Delamination not an issue } \\
\text { - No dry-out } \\
\text { - Lower thermal resistance than greases }\end{array}$ & $\begin{array}{l}\text { - Lower thermal conductivity than greases } \\
\text { - Surface resistance can be greater than greases. Can be } \\
\text { reduced by thermal pre-treatment } \\
\text { - Constant pressure required which can cause mechanical } \\
\text { stresses } \\
\text { - Voids can result with thermal cycles and subsequent phase } \\
\text { changes that cannot be refilled }\end{array}$ \\
\hline & & $\begin{array}{l}\text { - Not messy } \\
\text { - easy to handle } \\
\text { - Eliminates problem of applying exact the amount of } \\
\text { grease with each application } \\
\text { - Conforms to surface irregularity before cure } \\
\text { - No pump-out or migration } \\
\text { - Resists humidity and other harsh environments } \\
\text { - Good dielectric properties } \\
\text { - Low modulus (stress) } \\
\text { - Can be easily cut to size of mounting surfaces }\end{array}$ & $\begin{array}{l}\text { - Curing required } \\
\text { - Thermal conductivity lower than grease } \\
\text { - Delamination can be a problem } \\
\text { - Do not flow freely } \\
\text { - Permanent clamping needed } \\
\text { - Higher cost than grease }\end{array}$ \\
\hline
\end{tabular}

- Viscosity - Viscosity of a PCM above phase change temperature should be high enough to prevent the interface material from flowing when placed in a vertical orientation, which could result in dripping or draining of the TIM out of the assembly [12].
- Operating temperature range - must suit application environment, for example the continuous use temperature range for Bergquist Sil-Pad® 2000 which is a silicone elastomer is quoted as -60 to $+200^{\circ} \mathrm{C}$ [13] whereas the figures for Chomerics Thermflow $^{\mathrm{TM}}$ phase change interface pads are -60 to $+125^{\circ} \mathrm{C}$ [14] . 
- Pressure - Mounting pressure due to clamping can make a significant difference in TIM performance and ability to conform to surfaces to minimise contact resistance. A soft silicone based gap filler such as Chomerics THERM-A$\mathrm{GAP}^{\mathrm{TM}}$ [15] can provide conformability at low pressure whereas, Chomerics CHO-TERM ${ }^{\circledR}$ T500 [16], a glass reinforced insulating pad requires high mounting pressures in order to effectively reduce contact resistance.

- Outgassing - This phenomenon is the release of volatile gases when materials are exposed to elevated temperatures and/or low atmospheric pressures. Most polymers, including elastomers [17], silicones [18], etc, outgas to some degree. This can be a concern in aerospace applications where outgassing is accelerated due to reduced pressures and may also cause problems within sealed cavity packages.

- Surface finish - Some TIMs fill large gaps in irregular surfaces better than others and the interaction of filler particles with the microscopic projections at the adjoining surfaces influences the level of compaction and wetting at the interfaces.

- Ease of application/installation - depending on the material, control of the amount of applied e.g. grease is important.

- Mechanical properties of the material - TIMs in paste or liquid state would need to be dispensed or printed. Although a higher filler volume fraction increases the thermal conductivity it also increases the viscosity of the mix making it more difficult to dispense.

- Long term stability and reliability -The TIM is required to perform consistently throughout the lifespan of the device. Electronic devices such as microprocessors are designed to survive typically for seven to ten years [19], whereas avionics and telecommunication devices are expected to survive for decades.

\section{- Cost}

There is a complex relationship between the variables outlined here which will determine the choice of interstitial material and ultimately, performance, cost and manufacturability concerns dictate the tradeoffs that are made during TIM selection for a particular application.

\section{Thermal Greases}

Thermal greases are generally made of two primary components i.e. a polymer base and ceramic or metallic fillers. Silicone is commonly used as the base for its good thermal stability, wetting characteristics and low modulus of elasticity [20]. Ceramic fillers such as alumina, aluminium nitride, zinc oxide, silicon dioxide and beryllium oxides have been used. Also silver and aluminium are common metallic fillers used. The base material and fillers are mixed to form a paste that can be applied to mating surfaces. When applied to "rough" surfaces that are pressed together, the grease flows into all the voids to remove the interstitial air.

In general the higher the loading (i.e. the filler fraction) in thermal grease, the higher is its thermal conductivity. However this is governed by the polymer viscosity and wettability. Particle size is also an important factor in the polymer mix as particles can act as spacers between the surfaces and affects the bond line thickness and hence the thermal resistance. It is also found [20] that an optimised particle size distribution provides the processing benefits of a lower viscosity material. By mixing particles of different sizes, a much lower viscosity can be achieved than with the same volume fraction of mono-sized particles.

Although a very thin thermal joint is possible the main disadvantage of greases is that any excess grease will flow out of the joint area past the edges which may cause contamination to other components. Thermal greases provide very low thermal resistance between reasonably flat surfaces. Grease does not provide electrical insulation between the two surfaces. Also with the presence of power cycling and expansion and contraction the grease will migrate due to the so-called "pump-out" effect [6]. It can also dry out over time which will eventually starve the joint of thermal conduction path. Furthermore, joint integrity has to be sustained by some means of mechanical hardware. The failure mechanisms are strongly dependent on the device temperature and number of on/off cycles. The pumpout and phase separation increase exponentially with temperature [21] and a rule of thumb is a twofold increase in degradation for every $10^{\circ} \mathrm{C}$ increase in the operating temperature of the TIM. Viswanath et al. [21] also found that power cycling between 0 and $100^{\circ} \mathrm{C}$ over 7500 cycles caused a 4 to 6 fold increase in thermal resistance. However they found negligible rise in resistance for a 0 to $80^{\circ} \mathrm{C}$ over 2500 cycles.

Khatri et al. [22] report a new type of grease based thermal interface material, which is dry to touch, MicroFaze ${ }^{\circledR}$. It is claimed to be the first nonsilicone thermal grease that can solve contamination and migration problems that are typically associated with silicone-based products. The product consists of an aluminium or Kapton substrate, coated on both 
sides with the non-silicone thermal grease that is naturally tacky but dry-to-the-touch. It's not waxbased and it is claimed to offer thermal conductivities in the range $0.9-5 \mathrm{~W} / \mathrm{mK}$ [23] and thermal resistance of $0.13-0.2{ }^{\circ} \mathrm{Ccm}^{2} / \mathrm{W}$ which is similar to that of modern grease products but without the issues outlined above.

\section{Phase Change Materials}

Phase change materials (PCM) have traditionally been low temperature thermoplastic adhesives that typically melt in the $50-80^{\circ} \mathrm{C}$ range [6] and come in a variety of configurations with fillers to enhance their thermal conductivity. However, other all-metal phase change materials have been developed that are based on low melting alloys and shape memory alloys. Phase change materials are generally designed to have melting points below the maximum operating temperature of the electronic component. Too low a phase change temperature however would raise the likelihood of the TIM to a phase change due to environmental high temperatures.

\section{Thermal pads}

The key feature of thermal pads is their ability to change their physical characteristics. At room temperature they are solid and firm and easy to handle. As the electronic component reaches its operating temperature, the phase change material softens and with the clamping pressure it eventually starts to flow like a grease into the voids in the joint. The material fills the air gaps and voids improving the thermal flow at the interface between components and heatsinks. They have an advantage over thermal greases in that they generally do not suffer from pump-out effects and dry-out problems [20].

\section{Low Melting Alloys (LMAs)}

Phase change thermal interface materials have been developed [24-27] based on low melting point alloys. The alloy used will depend on the application. Alloys will need to be in a liquid state below the operating temperature of the electronic component to flow into all the surface asperities. Bismuth, indium, gallium and tin based alloys are amongst the commonly used alloys [24]. Cadmium, lead and mercury based alloys are generally avoided due to their toxicity and environmental issues.

LMAs provide an all metal heat path similar to solders but LMAs are formulated to melt below the operating temperature of the device and since they contain no organic materials, do not require curing during application. LMAs however have their drawbacks. Drip-out can be a problem particularly in vertically oriented interfaces [25]. Thermal cycling has been shown to lead to creation of voids in the interface. Intermetallic growth, oxidation/ corrosion also lead to the gradual decrease in performance and the eventual thermal failure [25]. Corrosion may however be minimised by using a near hermetic seal between the package lid and package substrate [26].

Several LMA phase change products have been marketed, targeting the CPU applications with their melting points approximately $20^{\circ} \mathrm{C}$ below the maximum operating temperatures of typical microprocessors: Enerdyne Solutions Indigo ${ }^{\mathrm{TM}}$ [26] and Thermax HiFlux [27] are two examples of such products. Indigo ${ }^{\mathrm{TM}}$ is available as a preform or preassembled with copper heat spreader. It is claimed to have advanced corrosion mitigation technology with thermal conductivities greater than $20 \mathrm{~W} / \mathrm{mK}$ and thermal resiatance less than $0.04^{\circ} \mathrm{C}-\mathrm{cm}^{2} / \mathrm{W}$ at clamping pressure of $\sim 70 \mathrm{kPa}$.

Webb et al. [24] have developed a high performance TIM consisting of a 25 micron coating of low melting temperature alloy (LMTA) tinned on each side of a 50 micron copper substrate. Thermal cycling tests however have shown degradation if temperatures are cycled $20 \mathrm{~K}$ above the melting point.

\section{Shape memory alloys}

Chen et al. patented a phase change thermal interface material [28] that includes a thermal grease and either one or a mixture of shape memory alloy particles dispersed in it. It is claimed that shape memory alloys enhance the thermal contact between the electronic device and the heatsink. This takes advantage of shape memory alloys (SMA) temperature-dependent martensitic phase transformation property. When the electronic device is in use, the rise in temperature causes the shape memory alloy to undergo a phase transformation from a low temperature martensitic phase to the high temperature austenitic phase. The SMA is dispersed in the thermal grease at the operating temperature of the heat source and applied at the interface between the heat source and the heatsink at the operating temperature of the device. It is subsequently cooled to solidify to form the interface. It is claimed that the above procedure results in the shape memory alloy to memorise the relative position of the TIM between the heat source and heat dissipating device to which it will return when heated. In this invention Chen et al., have used silver colloid or silicon colloid as the thermal grease and experimented with SMA fillers such as nano-CuNiTi, nano-CuAlZn, 
and nano-NiTiAlZ with particle diameters ranging from 10 to 100 nanometres.

\section{Exfoliated Clay}

Matabayas et al. [29] have patented a nanocomposite PCM that is comprised of one or more polymers, thermally conductive fillers and exfoliated clay materials. The process of exfoliation of the clay into the thermal interface material causes the clay particles to become dispersed as very small platelets with aspect ratio higher than 200 and high surface area. Because of this high aspect ratio only small amounts of clay particles less than $10 \mathrm{wt} \%$ is required to make significant improvement in the thermal performance of the TIM. It is also claimed that these particles slow the diffusion of oxygen and water through the interface material. The release of volatile components is also slowed improving the reliability and performance of TIM from reduced pump-out and dry-out.

\section{Fusible/non-fusible fillers}

Jayaraman et al. [30] patented a thermal interface material made of a polymer such as silicone combined with fusible fillers, such as solder powders, which form a polymer-solder hybrid TIM. During curing, the solder particles reflow to fuse together forming a network of high thermal conductivity structure. Non-fusible fillers may also be added to create a blend of fusible and non-fusible fillers in the phase change material to strengthen the TIM mechanical properties. The non fusible particles will also add to the thermal conductivity of the matrix as heat is conducted by percolation (i.e. the point-to-point particle contact). Non-fusible particle filler materials tested include aluminium or zinc oxide, aluminium, boron nitride, silver, graphite, carbon fibres, diamond, and metal coated fillers such as metal coated carbon fibre or metal coated diamond. They recommend fusible filler in the range of approximately $60-90 \mathrm{wt} \%$ and that of non-fusible filler of $5-50 \mathrm{wt} \%$ in the thermal interface material.

It is claimed that mixing fusible and non-fusible fillers offers a TIM with higher overall conductivity than a TIM filled with non-fusible particles for a given amount of filler by percent weight.

\section{Thermally Conductive Elastomers (Gels)}

Thermally conductive elastomeric pads generally consist of a silicone elastomer filled with thermally conductive ceramic particles and may be reinforced with woven glass fibre such as Chomerics THERMA-GAPTMF574 thermally conductive elastomer [31] or dielectric film such as Thermaflow 8024SPK series using Kapton for mechanical strength [32]. Since elastomers provide electrical insulation, they are generally used under devices that require electrical isolation. Elastomeric TIMs do not flow freely like greases and to conform to surface irregularities will require sufficient compressive load to deform [33]. At low pressures the elastomer cannot fill the voids between the surfaces and the thermal interface resistance is high. As pressure is increased, more of the microscopic voids are filled by the elastomer and the thermal resistance decreases [33]. A permanent mechanical fastener is required to maintain the joint once assembled. The thermal resistance achieved is dependant on thickness, clamping pressure and bulk thermal conductivity. For example, the Chomerics THERMA-GAPTMF574 at a clamping pressure of $70 \mathrm{kPa}$ can yield thermal resistances in the range 3.9$10.3^{\circ} \mathrm{Ccm}^{2} / \mathrm{W}$ for material thicknesses between 0.51 $2.5 \mathrm{~mm}[31]$.

\section{Carbon Based TIMS}

\section{Carbon fibre/nano-fibre}

While metallic interface materials such as solder are attractive because of their thermal conductivity, their high melting temperature can be problematic in die attach applications. The CTE mismatch between the die and substrate can cause stress damage between the materials as they cool. Hammel et al. [34] have developed a carbon nano-fibre reinforced thermal grease based on silicone free matrix such as epoxy. This is claimed to have resulted in an interface material without pump-out issues and with thermal resistances comparable to the best commercially available pastes. High thermal performance materials containing high thermal conductivity graphite have also been developed by Btechcorp [35] with interface resistance values in similar range to solder but without the associated residual stresses. They have developed a process for aligning high-density carbon fibres through the thickness of an uncured adhesive film with up to $3.1 \mathrm{~m}$ fibres per square $\mathrm{cm}$. Energy Science Laboratories, Inc. (ESLI) [36] have developed a high-conductivity, ultra-compliant thermal interface material, Vel-Therm ${ }^{\mathrm{TM}}$ for attachment of electronic components to heatsinks and heatspreaders. This material consists of numerous high thermal conductivity carbon fibres aligned perpendicularly to a substrate and fixed in position by a thin layer of adhesive. They are fabricated by precision cutting continuous tows of carbon fibre and electrostatically flocking the fibres into uncured adhesive using proprietary techniques to form a velvet like structure 
[37]. Substrates include metal foils, polymers, and carbon sheets with adhesives such as silicones, epoxies and ceramic adhesives Fibres bend independently in order to span the local gap. Low contact pressure is needed to ensure that each fibre will touch both surfaces. ESLI claim to have achieved thermal conductivities as high as 200W/mK [37].

To improve the thermal performance of vertically aligned carbon nano-fibres (VACNFs) Ngo et al. [38] filled the gaps between the fibres with copper. Copper was used as a gap-fill material to enhance the lateral heat spreading and also provide mechanical stability. This technique gives increased contact surface area to the target material. Experimental results have demonstrated trends indicating viability of these composites as a thermal interface material. It is claimed to yield thermal resistance values of $0.25^{\circ} \mathrm{Ccm}^{2} / \mathrm{W}$ with the particular contact measurement technique at clamping pressures of $\sim 414 \mathrm{kPa}$.

\section{Graphite flakes}

There are also other graphite based TIMs developed which are fabricated from highly pure graphite flakes in the form of flexible sheets [39]. A collection of exfoliated graphite flakes so called worms are compressed together without a binder to form a cohesive flexible sheet [40-42]. These flexible materials were originally intended for gaskets for fluid sealing applications such as head gaskets for internal combustion engines [40]. These materials are naturally porous and this characteristic has been exploited to develop specific grades of flexible graphite sheets [40] for TIM applications by impregnating the sheets with polymers such as mineral or synthetic oils to improve its performance. Smalc et al. [40] achieved thermal conductivities of around $5.7 \mathrm{~W} / \mathrm{mK}$ using a $0.13 \mathrm{~mm}$ thick polymer impregnated 1200 series Graphite sample from Graftech Inc [41]. Flexible graphite is effective as a thermal interface material if the thickness is low $(0.13 \mathrm{~mm})$ [42]. However it also requires higher contact pressure than other interface materials and is attractive for its thermal stability.

\section{Carbon nanotubes}

Carbon nanotubes are a form of pure carbon which look like a powder or black soot, but in actual fact they are hollow strands, thousands of times thinner than a human hair [43]. CNTs have onedimensional structures with diameters ranging from $1 \mathrm{~nm}$ to several nanometers and lengths from $100 \mathrm{~nm}$ to hundreds of microns. A single-walled carbon nanotube(SWNT) consists of a single sheet of graphene that is rolled into a cylindrical shell with a diameter of about $1 \mathrm{~nm}$. A multi-walled CNT is however a stack of graphene sheets wrapped into concentric tubes with a diameter in the order of 10 $\mathrm{nm}$. The walls of each layer are parallel to the central axis.

Mutiwalled carbon nanotubes (MWNT) can have thermal conductivities as high as $3000 \mathrm{~W} / \mathrm{mK}$ in the axial direction for individual multiwalled nanotubes[44]. However, taking into account the volume filling fraction of the CNTs the effective thermal conductivity is $\sim 200 \mathrm{~W} / \mathrm{mK}$ [45]. Other reports suggest that conductivities can be as low as $15 \mathrm{~W} / \mathrm{mK}$ [45] and $27 \mathrm{~W} / \mathrm{mK}$ [46] for discrete MWNTs. This wide variation can be attributed to the inherent disordered nature of CNTs grown using CVD processes [38].

Microprocessor manufacturers have been exploring the possibility of using CNT based polymer composites [47] as the thermal interface material between a microprocessor chip and the heat sink. Intel announced as early as 2002 [10] their interest in developing carbon nanotube TIMs either by designing a polymer film containing billions of nanotubes or developing a way of depositing them directly upon the silicon substrate. Also it has been reported [48] that Infineon Technologies AG will be using carbon nanotubes in a line of their power devices.

There has been a great deal of research carried out to formulate thermal interface materials containing carbon nanotubes [43]. Most common nanotube based TIMs fall in three main categories. In order of manufacturing complexity these are: homogenous mix of CNTs and CNT with metallic particles within a polymer matrix [47,10,49-52], vertically aligned growth of CNTs on a substrate [53-59] and more recently aligned growth on both surfaces between a chip and a heat spreader [59$61,44]$. A review of the literature detailing these developments is given below.

$\mathrm{Hu}$ et al. $[49,50]$ have used multiwalled CNTs as a filler in standard mechanically compliant matrix material such as silicone oil filled with thermally conductive particles such as nickel [49] and $\mathrm{ZnO}$ [50]. $\mathrm{Hu}$ et al. found that the rheological and mechanical properties of CNT filled TIMs become unacceptable beyond 3\% volume concentrations of CNT. At levels below 3\% of CNT, the increase in the effective conductivity that can be achieved is less than a factor of two compared to that of the traditional TIM composites with the same amount of Ni spheres but with no CNTs. 
Although CNTs have exceptional chemical and physical properties, they are not easily incorporated into other materials due to their poor dispersion within a matrix and poor adhesion to the host material [51]. Zyvex have developed a technology, Kentera $^{\mathrm{TM}}$ that provides both adhesion and dispersion of CNTs to the matrix. Using this process Zyvex claim to have managed to successfully suspend highly concentrated amounts of carbon nanotubes (CNTs) in solvents [52]. This technology has been incorporated into most polymer matrices, including epoxies, adhesives, polyurethanes and thermoplastics. Using Kentera ${ }^{\mathrm{TM}}$ they have produced a SWNT/polyurethane composite mixture which is cast in the form of a flexible, semi adhesive material whose thermal conductivity is claimed to be 4 times that of polyurethane.

$\mathrm{Hu}$ et al. [53] have also developed a technique that uses carbon nanotubes that are grown vertically from one surface and forced into contact with the opposing surface. This technique yields high effective thermal conductivity in the direction of propagation. The flexible nature of the CNT also yields lower thermal stresses. There still remains the challenge of reducing the thermal resistance between the CNT and the opposing surface. Hu et al. [53] found that the contact thermal resistance between the vertically aligned CNT film and the surface to be very large even with increased contact pressure. They have construed that this problem may be due to the non uniform height of the CNTs in the film, resulting in not all CNTs contacting the opposing surface.

Montgomery et al. [54] of Intel patented an invention that relates to a process of forming a TIM containing carbon nanotubes. A polymeric material such as polycarbonate, polypropylene or acetal is injected around bundles of aligned nanotubes grown on a substrate to produce a polymeric/carbon composite. The supporting substrate upon which the nanotubes were originally formed is removed by a mechanical grinding or chemical etching process and the resulting film placed between the electronic device and a heatsink or other cooling structures.

Lee et al. [55] developed a TIM matrix with Ethylene Vinyl Acetate (EVA) resin filled with carbon nanotubes and liquid crystal(LC). The well ordered alignment of the CNTs is achieved by the LC microstructure to form a well ordered CNT-LC matrix which is claimed to have thermal conductivity 3 to 5 times higher than some traditional TIMs.

Matabayas [56] has also filed an invention whereby a thermal interface material has been prepared with aligned carbon nanotubes. Carbon nanotubes are combined with an alignment material such as clay or liquid crystal material. When the alignment material is aligned it causes the carbon nanotubes to become aligned and hence conduct heat more efficiently. It is reported that in a formulation comprising of silica clay and single walled carbon nanotubes, mixed with an alpha-olefinic resin matrix, thermal conductivities in excess of $100 \mathrm{~W} / \mathrm{mK}$ were achieved.

Osiander et al. patented a method for creating a thermal interface material which included an array of perpendicularly aligned carbon nanotubes from a substrate [57]. Uniformly spaced metal catalyst particles are deposited on a substrate and carbon nanotubes are grown on the particles using chemical vapour deposition. In one scheme, metal catalyst particles are arranged with a particular ligand on a fluid surface of a Langmuir-Blodgett trough forming uniformly spaced particles with the spacing based on the particular ligand. Using this method they produced a TIM with CNT packing ratio greater than $50 \%$.

Damon [58] describes an invention relating to a thermal interface material comprising of conductive nanostructures aligned with the application of an electric field. Single walled carbon nanotubes, multi walled carbon nanotubes and silver nano-fibres have been included within a matrix material which acts as the wetting and supporting agent for the conducting components.

In another development a process has been described where an integrated circuit package is formed that utilises a thermal interface material layer containing an aligned array of carbon nanotubes [59]. A diamond layer is formed on a heatsink or heatspreader by chemical vapour deposition(CVDD). An array of carbon nanotubes is then grown by a plasma discharge process on the surface of the CVDD layer or on the surface of the die. The two are then fastened together with the nanotubes thermally coupling the surfaces of the die and heatsink.

Researchers from Stanford University [59-61] have discovered that adding oxygen to the gas mixture during plasma-enhanced chemical vapour deposition can boost the growth of vertical arrays of SWNTs. The process grew densely packed SWNTs over 4 inch wafers of $\mathrm{SiO} 2 / \mathrm{Si}$ coated with iron clusters of about $1.3 \mathrm{~nm}$ in diameter. The diameter of these hollow, single-walled fibres is 10,000 times smaller than that of a human hair. They have also developed a method for lifting the nanotubes off their original growth substrate and transferring them 
onto materials incompatible with the high temperatures required for nanotube growth such as plastics and metals. The group have begun tests to determine the effectiveness of these SWNT wafers as a thermal interface material, conducting and dissipating heat away from computer chips.

Zhang et al. [62] used multi-walled carbon nanotubes (MWNT) and carbon black in a thermal interface material specifically formulated for use in a high brightness light emitting diode(HB-LED) packaging. The particular formulation comprised of $2 \mathrm{wt} \%$ of MWNT and $10 \mathrm{wt} \%$ carbon black as fillers in an epoxy resin matrix to form the TIM. The mixture was optimised to have a curing temperature of $140{ }^{\circ} \mathrm{C}$ and glass transition temperature of $147^{\circ} \mathrm{C}$ suitable for HB-LEDs.

There has evidently been a growing interest in carbon nanotubes due to their unique thermal and rheological properties. CNTs are obviously attractive in thermal interface materials applications. However though research in this field is ongoing, widespread use of carbon nanotube based TIMs seems a long way off [63].

\section{Discussion and Conclusions}

The total thermal resistance of an electronic assembly generally comprises of the thermal resistance of the device itself, the TIM thermal resistance which includes the interface contact resistances and the heat dissipation to the ambient. As an example, it has been reported [64] that for a Pentium 2 processor, the TIM accounted for $15 \%$ of the total allowable thermal resistance and if the same TIM had been used for a Pentium 4, with $6.1 \%$ increase in heat flux, then the TIM would have used $80 \%$ of the thermal budget. And, as it is clear increase in power dissipation is a trend that is set to continue and as such there is going to be a need for thermal interface materials with higher performance, lowest thermal resistance and long term reliability.

Conventional thermal interface materials have been reviewed and developments in each TIM category has been explored.

Since the discovery of carbon nanotubes and the realisation of their potential in the manufacture of thermal interface materials, there has been a growing level of research activity in this area. Many research papers have been published and patents filed some of which have been detailed in this article. However, it is apparent that great many challenges will need to be overcome before CNT based TIMs can be available that can be easily applied and with the expected reliability. One such challenge is in the case of vertically oriented CNTs that are grown from one surface and forced into contact with an opposing surface. Although this technique can potentially yield high thermal conductivity in the direction of propagation, achieving low thermal resistance between the CNTs and the interface opposing the growth surface remains a challenge [65].

\section{References}

1. http://processorfinder.intel.com/scripts/details.asp?sSp $\underline{\mathrm{ec}=\mathrm{SL} 264 \& \text { ProcFam }=47 \& \mathrm{PkgType}=\mathrm{ALL} \& \text { SysBusSp }}$ $\mathrm{d}=\mathrm{ALL} \& \operatorname{CorSpd}=5018$

2. http://en.wikipedia.org/wiki/List_of_Intel_Xeon_micr oprocessors

3. Haque, A.H., "Processing and Characterization of Device Solder Interconnection and Module Attachment for Power Electronics Modules", $P h D$ Thesis, Chapter IV, pp. 82, 1999. http://scholar.lib.vt.edu/theses/available/etd-0107100102125/

4. B. Roehr, "Mounting Considerations for Power Semiconductors", Motorola Application Note AN1040.

5. Catalog \#87-HS-9, pp. 8, Thermalloy Inc., Dallas, TX, 1987.

6. Blazej, D., Thermal Interface Materials", Electronics Cooling, Vol. 9, No. 4, pp. 14-20, November 2003.

7. Latham, C.A., "Thermal resistance of interface materials as a function of pressure", Electronics Cooling, September 1996.

8. Lasance, C.J.M., "Problems with Thermal Interface Material Measurements: Suggestions for Improvement", Electronics Cooling, November 2003.

9. Zweben, K., "Thermal Materials Solve Power Electronics Challenges", Power Electronics Technology, February 2006, pp. 40-47. Also at: http://powerelectronics.com/thermal_management/hea tpipes spreaders/power thermal materials solve/

10. Hachman, M., "Intel Adapting Buckyballs for Cooling Chips", ExtremeTech, February 2002. http://www.extremetech.com/article2/0,1697,27658,0 0.asp.

11. Bergquist Thermal Materials: Hi-Flow Products http://www.bergquistcompany.com/tm hi flow detail .cfm?oid=104290\&tab=faqs\&prod type=hiflow

12. Kranz, R., "Thermal interface materials for highpower BGAs, Careful planning can prevent increased manufacturing costs and field failures", Advanced Packaging, April, 2000, also at: http://ap.pennnet.com/Articles/Article_Display.cfm?S ection=Archives\&Subsection=Display\&ARTICLE _ I $\mathrm{D}=75689$ \&KEYWORD $=$ thermal $\% 20$ interface $\% 20$ for \%20higher\%20power\%20bga

13. http://www.bergquistcompany.com/tm_sil_pad_detail. cfm?oid=104259

14. http://www.chomerics.com/products/thermflow310.ht $\mathrm{m}$

15. http://www.chomerics.com/products/therm gapfillers. $\underline{\mathrm{htm}}$

16. http://www.chomerics.com/products/chotherm500.ht $\underline{\mathrm{m}}$ 
17. Outgassing and Weight Loss of Elastomers, http://www.pspglobal.com/outgassingelastomers.html

18. Riegler, B., "Low Outgas Silicone Pressure Sensitive Adhesive for Aerospace Applications II", http://www.nusil.com/whitepapers/index.aspx

19. Mahajan, R. et al., "Thermal Interface Materials: A Brief Review of Design Characteristics and Materials", Electronics Cooling, February 2004.

20. Becker, G. et al., "Thermal Conductivity in Advanced Chips, Emerging Generation of Thermal Greases Offers Advantages", Advanced Packaging, July 2005. http://ap.pennnet.com/Articles/Article Display.cfm?S ection=Articles\&Subsection=Display\&ARTICLE ID $=231839$.

21. Viswanath, R. et al., "Thermal Performance Challenges from Silicon to System", Intel Technology journal Q3, 2000.

22. Khatri, P. et al., "Dry-to-the-Touch Thermal Grease Cuts Installation Mess", TDI Power Electronics Technology, Aug 1, 2002. Also found in: http://www.powerelectronics.com/thermal manageme $\mathrm{nt} /$ thermal interface materials/power_drytothetouch $\mathrm{t}$ hermal_grease/index.html

23. AOS Thermal Compounds: http://www.aosco.com/products/microfaze/

24. Webb, R. L. et al., "Low Melting Point thermal Interface Material", ITHERM 2002, 8th Intersociety Conference on Thermal and Thermomechanical Phenomena in Electronic Systems, May 30-June 01, pp. 671-676.

25. Macris, C. et al., "Performance, Reliability, and Approaches Using a Low Melt Alloy as a Thermal Interface Material", IMAPS 2004, $37^{\text {th }}$ Int. Symp. On Microelectronics, nov 14-18, long Beach, Ca.

26. http://www.enerdynesolutions.com/prod indigo.html

27. http://www.thermaxkorea.com/products/p intro.html

28. Chen, G., "Thermal Interface Material and Method for Manufacturing", US patent no. US2005/0245659A1, Nov. 3, 2005.

29. Metabayas, J. et al., "Phase Change Thermal Interface Materials Including Exfoliated Clay", US patent no 6,924,027, Aug. 02, 2005.

30. Jayaraman S. et al., "Phase Change Material Containing Fusible Particles as Thermally Conductive Filler", US patent no 6,926,955 B2, Aug 9, 2005.

31. Chomerics Products Library: http://www.chomerics.com/products/documents/tb70. pdf

32. Thermafl Interface Materials: http://www.thermaflo.com/ifmat elastomeric.shtml

33. De Sorgo, M., "Thermal interface materials", Electronics Cooling, Vol. 2, No. 3, pp. 12-16, September 1996.

34. Hammel, E. et al., "Carbon Nanofibers for Thermal Interface Materials in Pressure Contacts", IMAPS, Palo Alto, CA, October 23-26, 2005.

35. http://www.btechcorp.com/tim.htm

36. http://www.esli.com/
37. Seaman, C.L., "Carbon Velvet Thermal Interface Gaskets" 39th AIAA Aerospace Sciences Meeting, Reno Nevada, Spacecraft Thermal Control and Technology Session. January 2001.

38. Ngo, Q. et al., "Thermal Interface Properties of $\mathrm{Cu}-$ filled Vertically Aligned Carbon Nanofiber Arrays ", Nano Letters, Vol. 4, No. 12, 2004, pp. 2403-2407.

39. Marotta, E.E. et al., "Thermal joint Conductance for Flexible Graphite Materials: Analytical and Experimental Study", IEEE Transactions on Components and Packaging Technologies, Vol. 28, No. 1, march 2005.

40. Smalc, M. et al., "Advanced thermal interface materials using natural graphite", Proc. International Electronic Packaging Technical Conference, July 0611, 2003, Maui, pp. 253-261.

41. www.graftechaet.com/upload/268.pdf

42. Xiangcheng, L. et al., "Electronic applications of flexible graphite", Journal of Electronic Materials, May 2002.

43. Stansberry, M., "Carbon nanotube technology, closer than you think", SearchDataCenter.com, 25 August 2005.

44. Kim, P. et al., "Thermal Transport Measurements of Individual Multiwalled Nanotubes", Phys. Rev. Lett., Vol.87 (2001), pp. 215502.

45. Yang, D.J. et al., "Thermal conductivity of multiwalled carbon nanotubes", Physical Review B, Vol. 66, pp. i.d. 165440, 2002.

46. Wang , X et al., "Thermal Transport in Multiwall Carbon Nanotubes", Proc. $37^{\text {th }}$ AIAA Thermophysics Conf., 2004.

47. http://www.azonano.com/details.asp?ArticleID=556

48. Lammers, D., "Nanotech begins journey from lab to fab", EE Times, Jan 2004.

49. Hu, X. et al., "Thermal Conductance of Particle Filled Thermal Interface Materials Using Carbon Nanotube Inclusions", Proc. $9^{\text {th }}$ ITherm Conference, Las Vegas, NV, 2004.

50. Hu, X. et al., "Composite Thermal Interface Material Including Particles and Nanofibers", U.S. provisional application 60/541,428, filed on Feb. 2, 2004.

51. Rutkofsky, M. et al., "Using Carbon Nanotube Additive to make a Thermally and Electrically Conductive Polyurethane", Zyvex application note 9711.

http://www.zyvex.com/Products/POLY 001a.html

52. http://www.zyvex.com/Products/applicationguidem.ht $\underline{\mathrm{ml} \# 1000}$

53. Hu, X. et al., "Thermal Characterisation of Aligned Carbon Nanotubes on Silicon", Proc. Semi-Therm, San Jose, CA, 2005.

54. Montgomery, S. et al., "Carbon Nanotube Thermal Interface Structures”, US Patent No. 6,965,513, November 2005.

55. Lee, T. et al., "High Thermal Efficiency Carbon Nanotube-Resin Matrix for Thermal Interface materials", Proc. 55th Electronic components and technology conference, 2005, pp. 55-59. 
56. Matabayas, J., "Thermal interface material with aligned carbon nanotubes", Patent No. WO 2005/031864.

57. Osiander, R. et al., "Method of making Carbon Nanotube Arrays, and Thermal Interfaces Using Same", Patent No. WO2005052179.

58. Damon, B., “Alligned Nanostructure Thermal Interface Material”, US Patent No. US2005/255304, 2005.

59. De Lorenzo, D.S. et al., "Increasing thermal conductivity of thermal interface using carbon nanotubes and CVD", United States Patent 6891724.

60. Dai, H., "Scientists find new method for creating high-yield single-walled carbon nanotubes", Stanford Report, October 26, 2005.

61. Zhang, G. et al., "Ultra-high-yield growth of vertical single-walled carbon nanotubes: Hidden roles of hydrogen and oxygen", PNAS, Nov 2005, Vol. 102, No. 45, 16141-16145.

62. Zhang, K. et al., "Study on Thermal Interface Material with Carbon Nanotubes and Carbon Black in HighBrightness LED Packaging with Flip-Chip Technology ", Proc. 55th Electronic components and technology conference, 2005, pp. 60-65.

63. Doe, P., "Packaging Technology Moves to Center Stage", WaferNews, February 2006.

http://72.14.207.104/search?q=cache:B9CSwPWjWN EJ:sst.pennnet.com/Articles/Article Display.cfm?Sect ion=HOME\&ARTICLE ID $=247956 \&$ VERSION N $\underline{\mathrm{UM}}=2 \& \mathrm{p}=67+\mathrm{AMD}+$ carbon + nanotubes + thermal + int erface \&hl=en\&gl=uk\&ct=clnk\&cd=10 .

64. Gwinn, J.P. et al., "Apparatus for Accurate Measurement of Interface Resistance of High Performance Thermal Interface Materials", ITHERM 2002, 8th Intersociety Conference on Thermal and Thermomechanical Phenomena in Electronic Systems, May 30-June 01, pp. 644-650.

65. Schelling, P.K. et al., "Managing heat for electronics", Material Today, June 2005. 